Evaluating Adolescent Decision Making in Legal Contexts

Author(s): Elizabeth S. Scott, N. Dickon Reppucci, Jennifer L. Woolard

Source: Law and Human Behavior, Vol. 19, No. 3 (Jun., 1995), pp. 221-244

Published by: Springer

Stable URL: http://www.jstor.org/stable/1394002

Accessed: 20/05/2009 04:58

Your use of the JSTOR archive indicates your acceptance of JSTOR's Terms and Conditions of Use, available at http://www.jstor.org/page/info/about/policies/terms.jsp. JSTOR's Terms and Conditions of Use provides, in part, that unless you have obtained prior permission, you may not download an entire issue of a journal or multiple copies of articles, and you may use content in the JSTOR archive only for your personal, non-commercial use.

Please contact the publisher regarding any further use of this work. Publisher contact information may be obtained at http://www.jstor.org/action/showPublisher?publisherCode=springer.

Each copy of any part of a JSTOR transmission must contain the same copyright notice that appears on the screen or printed page of such transmission.

JSTOR is a not-for-profit organization founded in 1995 to build trusted digital archives for scholarship. We work with the scholarly community to preserve their work and the materials they rely upon, and to build a common research platform that promotes the discovery and use of these resources. For more information about JSTOR, please contact support@jstor.org. 


\title{
Evaluating Adolescent Decision Making in Legal Contexts*
}

\author{
Elizabeth S. Scott, $\uparrow$ N. Dickon Reppucci, $\ddagger$ and \\ Jennifer L. Woolard $\ddagger$
}

Challenges the use by policy researchers of a model for comparing adolescent and adult decision making that is based on informed consent standards. An expanded decision-making framework designed to evaluate "judgment" in adults and adolescents can better test the empirical basis of paternalistic legal policies. The theoretical and empirical literature on the informed consent framework is critiqued and an alternative framework incorporating judgment factors is proposed. Three judgment factors-temporal perspective, attitude toward risk, and peer and parental influence-and their effects on decision making are explored. Finally, implications for future research are analyzed in several decision-making contexts.

Adolescents pose a dilemma for legal policymakers. Traditionally they have been classified with younger children as minors, and been denied legal rights and privileges accorded to adults. However, most would agree that presumptions of vulnerability, dependence, and incompetence that justify paternalistic legal policies seem less valid when applied to adolescents (Zimring, 1982). Some observers (e.g., Melton, 1983a, 1983b) have argued that adolescents' legal treatment is unduly restrictive and that they should be given more of the rights and privileges

\footnotetext{
* Several of the ideas in this article were originally presented by the first author and were published as part of a symposium on competence (see Scott, 1992). The current article expands and refines these ideas, provides a more substantial research base, and suggests several future research directions. We thank Joseph Allen, Richard Bonnie, Baruch Fischhoff, William Gardner, John Monahan, Edward Mulvey, Richard Redding, Paul Slovic, and three anonymous reviewers for their helpful comments. Special thanks to Thomas Grisso for providing much constructive criticism and to Wendy Shang for outstanding research assistance. Finally, we would like to acknowledge the MacArthur Foundation, which supported this work in its early stages. Address reprint requests to Elizabeth $S$. Scott, School of Law, University of Virginia, Charlottesville, VA 22903.

† School of Law, University of Virginia.

$\ddagger$ Department of Psychology, University of Virginia.
} 
accorded to adults. Others (e.g., Dowie, 1993; Moseley-Braun, 1994; Regnery, 1989), alarmed by the social costs of juvenile crime, argue that the law protects adolescents excessively from the consequences of their conduct, and that they should be held responsible for the harms that they cause in the same manner as adults.

These critics of paternalistic legal policies are likely to diverge in their political agendas, but their arguments share an important empirical premise-that adolescent decision making is more like that of adults than the law has assumed. Some advocates for adolescent self-determination have been explicit in making this claim. For example, on the issue of abortion, reformers (Interdivisional Committee on Adolescent Abortion, 1987) argue that developmental theory and empirical research demonstrate that by midadolescence, minors are indistinguishable from adults in their decision making. Their capacity for reasoning and understanding is similar to that of adults, and thus, they meet adult standards of legal competence under informed consent doctrine (Gittler, Quigley-Rick \& Saks, 1990). Under this argument, the case of different legal treatment, to the extent that it is based on a presumption of incompetence, is greatly weakened (Hartigan $v$. Zbaraz, A.P.A. amicus curiae brief; Melton, 1983a, 1983b). This argument has been extended to challenge a wide range of restrictive paternalistic policies directed at children and adolescents.

Our purpose is to challenge the usefulness of this approach to evaluating adolescent decision-making capacity and to suggest an expanded framework that will allow researchers to contribute more effectively to the development of empirically accurate legal policies. Our challenge is twofold. First, we believe that advocates' claims exaggerate the scientific evidence that no differences distinguish the decision making of adults and minors under informed consent tests. Second, and of greater importance for our purposes, the informed consent model incorporates a narrower range of decision-making factors than appear to be relevant to courts and policymakers, and thus its utility is somewhat limited.

Informed consent standards of legal competence, and the model based on these standards, focus on two aspects of cognitive functioning - capacity for reasoning and understanding. Protective legal policies directed toward minors, however, are based not only on the presumption that adolescents differ from adults in these capacities, but also that their choices and behavior are affected, in ways that distinguish them developmentally from adults, by other decision-making factors that are not included under an informed consent model. For example, adolescents are presumed to be more susceptible to peer influence (Lee v. Weisman, 1992); to have a tendency to focus more on immediate rather than long-term consequences (Zimring, 1983); and to be less risk averse and thus more inclined to make risky choices than are adults (Gardner \& Herman, 1991). Our goal is to propose a model to compare adolescent and adult decision making that incorporates this broader range of factors - peer (and parental) influence, risk preference and perception, and temporal perspective - as well as those included under an informed consent model.

For want of a better designation, we call our approach a "judgment" model, a term that requires some clarification. Our intent is to use the term in its ordinary 
"lay" sense, which, in our view, captures the quality that judges and policymakers who are inclined to treat adolescents paternalistically believe distinguishes adolescent and adult decision making. The intuition underlying legal paternalism, we believe, is that minors, for developmental reasons, tend to use immature judgment and to make "poor" choices that may result in negative health or legal consequences. The decision-making factors noted above are components (although surely not the only elements) of this construct of "judgment." We are not using the narrower more precise meaning of judgment employed in decision theory and research which focuses on the process of assessing matters of fact (Kahneman, Slovic, \& Tversky, 1982).

Our proposal and argument are largely positive rather than normative. That is to say, we do not advocate the use of judgment as a basis for policies distinguishing between adolescents and adults. Rather, we are suggesting that researchers who are interested in informing legal policy in this area will contribute more usefully if they study those aspects of decision making that in fact are important to courts and policymakers. Our effort in proposing the model is to present somewhat systematically what we take to be the relevant factors.

A road map of this article may be helpful. First, we sketch briefly the decision-making framework derived from informed consent doctrine, and critique the theoretical and empirical evidence about adolescent decision making under this framework. We than explain why this framework is incomplete as a basis for comparing adolescent decision making with that of adults, and propose a detailed alternative judgment framework. After describing several developmentally linked factors that are believed to affect minors' judgment-temporal perspective, attitude toward risk, and the value attached to peer and parental approval-we explore how these factors could affect decision making. Finally, we analyze the implications for future research of conceptualizing decision making in this way and propose several directions for research based on this framework.

\section{EVALUATION OF DECISION MAKING UNDER THE INFORMED CONSENT FRAMEWORK}

Informed consent doctrine requires that medical treatment be premised on knowing, voluntary, and competent consent. If minors are to have independent authority to make medical decisions, including those involving abortion and contraception, they must be competent. Thus, it is not surprising that those promoting greater self-determination for minors have tried to demonstrate that adolescents are competent under the legal tests. Further, it is understandable that adolescent competence in general has come to be analyzed in an informed consent framework, because the standard provides a guide for measuring competence, which in other contexts of legal policy toward minors is vaguely defined. The law does not prescribe precisely, for example, what capabilities make a teenager, but not a 5-year-old, competent to decide about her custody when her parents divorce. Informed consent tests have come to serve as a general proxy of compe- 
tence in evaluating adolescent decision making. Most empirical research has employed this framework - and indeed, most has focused on medical decision making.

\section{The Informed Consent Framework}

Tests of competence under informed consent doctrine are designed to evaluate the process of decision making under a rational decision-making model. Although the emphasis varies depending on the test, modern constructs focus on the following elements: an understanding of relevant disclosed information about the treatment, an ability to appreciate its relevance to one's own situation ("deep" understanding), and an ability to use the information in comparing alternative options and in weighing their risks and benefits in making a choice (Appelbaum \& Grisso, 1988). Tests of competence under informed consent doctrine focus on the process of decision making and exclude emphasis on outcome ${ }^{1}$ (Appelbaum, 1987; President's Commission, 1982; Roth, Meisel, \& Lidz, 1977), a focus that protects the autonomy interest of individuals making decisions about medical interventions (Appelbaum, 1987; Katz \& Capron, 1975; Meisel, 1979). A strong norm supports the position that choices about treatment should reflect the subjective values and preferences of decision makers, and that no objective (external) measure of outcomes is appropriate.

\section{A Scientific Critique of Informed Consent Research}

Applying this framework, advocates of adolescent self-determination on issues such as abortion have drawn on child development theory and empirical research to argue that no significant differences separate adolescents and adults in their capacity to make informed medical decisions. In our view, although the limited relevant research generally supports their position, these advocates exaggerate the robustness of the scientific evidence. We concur with Gardner, Scherer, and Tester's (1989) careful and persuasive argument that advocates (e.g., Interdivisional Committee on Adolescent Abortion, 1987) overstep the limits of science in claiming that the research demonstrates that no differences distinguish the decision-making capability of adolescents and adults. ${ }^{2}$ We highlight and expand upon the important points of this critique.

First, the early researchers (e.g., Weithorn \& Campbell, 1982; Grisso \& Vierling, 1978) relied on the principles of Piaget's stage theory of cognitive de-

\footnotetext{
${ }^{1}$ Traditionally, the reasonableness of the outcome was accepted as a standard of competence. In general today, however, informed consent tests exclude consideration of outcome. Some courts, of course, in assessing competence in individual cases, may be influenced by the reasonableness of the outcome.

${ }^{2}$ In our view, it is unfortunate that the most prominent application of social science research to legal policy in this area has been on the issue of abortion decision making. The ideological and highly controversial nature of this issue has distorted scientific discourse, because opinion on the underlying issue tends to color the response to the use of empirical data. Particularly, supporters of adolescent self-determination may find it difficult to criticize the scientific basis of advocates' arguments. For this reason, Gardner and his colleagues are to be commended.
} 
velopment (Flavell, 1985; Inhelder \& Piaget, 1952) that are no longer widely accepted among cognitive psychologists (Gardner et al., 1989). These researchers linked competence to make informed medical decisions to the formal operations stage of cognitive development (that children reach between the ages of 11 and 14). At this stage, Piaget posited, children can think hypothetically about a problem and consider alternative solutions, weighing and comparing consequences. Today, few psychologists believe that children at a given stage engage in a characteristic reasoning across many tasks and that this process differs from reasoning at other stages. Rather, collaborative models which include organismic and environmental components have been proposed (Fischer \& Silvern, 1985), and most psychologists believe that similar skills develop at different rates in different task domains (Flavell, 1985; Siegler, 1991). This conception does not support the notion of a cognitive ability (i.e., to engage in formal operations) that is linked to general decision-making capacity. Moreover, research on decision making under conditions of uncertainty indicates that neither adolescents nor adults perform at an optimal level under many circumstances involving complex decisions (Shaklee, 1979; Kahneman et al., 1982). Adolescents and adults may differ in their ability to perform at optimal capacity; personal and environmental characteristics may differentially enhance and impair performance. Thus, a finding of competence to make one kind of decision may not be generalizable to other decisions in other contexts.

Even if the theoretical foundation were more credible, only a handful of studies have compared decision making by adults and adolescents in legally relevant contexts, and most have examined only a small number of subjects ${ }^{3}$ (Ambuel \& Rappaport, 1992; Garrison, 1991; Lewis, 1980; Scherer, 1991; Weithorn \& Campbell, 1982). Furthermore, many of the studies provide only indirect evidence that adolescents are competent decision makers. A few studies compare the comprehension of adults and minors in legal settings, but do not focus on decision making (Belter \& Grisso, 1984; Grisso, 1980), and a few examine adolescents' understanding of treatment issues, but do not compare adolescents and adults (Kaser-Boyd, Adelman, \& Taylor, 1985; Kaser-Boyd, Adelman, Taylor, \& Nelson, 1986). Although several studies found differences between older and younger adolescents (Ambuel \& Rappaport, 1991; Belter \& Grisso, 1984; Garrison, 1991; Scherer, 1991), suggesting that the methodologies were not necessarily insensitive to differences, a great deal more empirical substantiation using convergent methodologies is needed.

A few studies have included factors outside the strict confines of the informed

\footnotetext{
${ }^{3}$ A number of studies address the general topic of adolescent decision making. The cognitive literature on decision making does include a number of studies on adolescents and their reasoning abilities, but they often focus on decisions that are not legally relevant (e.g., career decision making, computer simulations). Other studies focus on a particular behavior (e.g., smoking, taking drugs) and examine antecedents and predictors of engaging in the behavior (e.g., Chassin, Presson, Sherman, \& Edwards, 1991), but do not examine the decision process per se. Although these studies do not directly address the issue of informed consent, some do provide information relevant to judgment factors, and they are addressed in a subsequent section of this paper.
} 
consent framework. For example, Lewis (1980), in a study of adolescent women awaiting results of pregnancy tests, examined knowledge of legal context and social influences upon their decision making. Ambuel and Rappaport (1992) studied adult and adolescent women contemplating a decision about an unplanned pregnancy and included an assessment of voluntary decision making, global quality of decision making, and consideration of immediate and long-term consequences. Both of these studies are consistent with our approach.

Other methodological factors limit the extent to which claims about adolescent competence can be drawn. Most studies were conducted in a laboratory setting in which subjects were provided with hypothetical treatment information (Belter \& Grisso, 1984; Garrison, 1991; Kaser-Boyd et al., 1985, 1986; Scherer, 1991; Scherer \& Reppucci, 1988; Weithorn \& Campbell, 1982). With few exceptions (e.g., Ambuel \& Rappaport, 1992), no adequate research compares adolescent and adult performance under conditions that adequately resemble daily life. Moreover, as Gardner et al. (1989) point out, much of the information about subjects' cognitive decision-making processes consists of retrospective selfreport, a poor substitute for contemporaneous observation. Furthermore, White middle class samples, which do not adequately represent adolescents of diverse racial, ethnic, and socioeconomic backgrounds, are the norm. As will be discussed later, it is possible that different cultural experiences may systematically affect decision-making ability and performance. Finally, the potential effects of problem framing (e.g., information presentation, question formation) have been documented (Fischhoff \& Quadrel, 1991; Kahneman et al., 1982), yet are rarely acknowledged, and comparative studies are few.

The upshot of this brief review of the current empirical picture is that scientific authority is at best tentative for the assertion that adolescents' capacities for reasoning and understanding in making decisions are similar to those of adults. It is clear that research should move beyond the Piagetian stage framework to examine differential capacity in various contexts. Generalizability and external validity would be enhanced by moving studies out of the laboratory to more ecologically valid situations and samples. In short, future research comparing adults and adolescents, using instruments designed to test competence in an informed consent framework (e.g., Grisso \& Appelbaum, 1992), is needed to establish a proposition that has come to be accepted as proven among advocates for adolescent self-determination.

\section{COMPETENCE AND JUDGMENT}

Even if further research confirms that adolescents and adults have similar abilities to understand disclosed information, to appreciate its meaning, and to make decisions through a rational process, this conclusion is not likely to resolve, in the minds of policymakers, the issue of whether adolescents should be accorded the same legal treatment as adults. Although the legal presumption that 
minors are incompetent and need legal protection rests in part on an intuition that their capacity for understanding and reasoning is less developed than is that of adults', it also rests on the belief that their judgment is less mature. In essence, the intuition behind paternalistic policies is that developmentally linked traits and responses systematically affect the decision making of adolescents in a way that may incline them to make choices that threaten harm to their own and others' health, life, or welfare, to a greater extent than do adults.

The view that minors need protection from the costs of immature youthful choices supported the establishment of a separate juvenile justice system in which adolescents who commit crimes are treated as less responsible than adults who engage in similar behavior. It also justifies the infancy doctrine in contract law under which contracts executed by minors are not enforceable. Finally, restrictions on adolescent liberty to make decisions about medical treatment, employment, marriage, and education can be explained as derived in part from these perceptions.

If our claim is correct, then the informed consent model is incomplete as a framework in which to compare the decision-making capacities of adolescents with adults. An approach that will be more useful to legal policymakers must incorporate a wide range of elements in the conceptual domain of decision making, including some that would be irrelevant or excluded under an informed consent framework. As suggested earlier, we propose a judgment framework that includes not only understanding and reasoning ability, but also such factors as conformity and compliance in relation to peers and parents, attitude toward and perception of risk, and temporal perspective. Focusing on these decision-making factors allows a comparison between the subjective values that drive the choices of adolescents and those of adults, a comparison that is excluded under even the most expansive test of competence in an informed consent framework.

It might seem that the test of competence under informed consent doctrine that focuses on appreciation is expansive enough to capture deficiencies in decision making that reflect immature judgment. Under this standard, the decision maker must not only understand factual information, but also be able to apply it to her own situation. Thus, in some sense, this test of competence requires greater "maturity" than other competence tests and may overlap to some extent with the judgment framework. However, in general, an adult would not be found incompetent under the appreciation standard because her decision departs from the norm as measured by the factors that are incorporated in the judgment framework. Rather, her choice would be protected as reflecting idiosyncratic subjective preferences.

A reasonable question, at this point, is whether policymakers' focus on adolescent judgment is justified, when the legal capacity of adults, by and large, is not evaluated in this way. For example, under informed consent doctrine, adults (in theory at least) are free to make poor decisions (from the perspective of others) based on idiosyncratic values, as long as their understanding and reasoning are not greatly impaired. Second-guessing of individual choices in this context is deemed an unacceptable burden on personal autonomy. 
Two arguments support the claim that the evaluation of adolescent legal capacity appropriately considers judgment as well as reasoning and understanding. The first is that a different response would carry a significant social cost. Informed consent policy reflects a conclusion that the importance of respecting adults' autonomy in the context of health care decisions outweighs the social cost of poor decisions by occasional "outliers", particularly given the substantial costs of any other approach. It is plausible to assume that most people are motivated to make health-promoting medical decisions (i.e., use good judgment), and thus that the social cost of respecting autonomy is tolerable. If adolescents as a class have poorer judgment (and choose different outcomes) than adults, then the social cost of according them freedom and of holding them to adult standards of responsibility might be significant. In fact, in many legal contexts, anticipated social cost of poor judgment by adults justifies restriction of freedom (e.g., seat belt and motorcycle helmet laws, product safety regulations) and reduced responsibility (e.g., laws allowing "cooling off periods" before enforcing door-to-door sales contracts). If immature adolescent decision making creates costs that fall primarily on minors themselves, then the societal interest in preventing harm to this group may be particularly acute.

The second argument for considering judgment hinges on an important distinction that can be drawn between the poor choices made by individuals and those that the law presumes are made by minors as a group. The adult's "poor" decision (to refuse recommended treatment, for example) is presumed to reflect the subjective values and preferences of the individual. In the case of the adolescent refusing treatment, the values and preferences are presumed to reflect common age-linked developmental characteristics that predictably will change. It is assumed that with maturity, most individuals will make a different choice. If this is so, then the autonomy claim seems less compelling than is that of adults. Moreover, implicit in the presumption that developmental factors affect judgment is a prediction (or hope, in the case of delinquent behavior) that the adolescent will become an adult with different values and preferences from her youthful self. If this is so, then the case for protecting the opportunities and prospects of that future adult from the costs of her immature youthful judgment and choices seems powerful (Scott, 1990).

Whether policymakers legitimately focus on minors' judgment is a political and moral question, not necessarily a scientific one; thus, whether arguments for paternalism are persuasive may largely depend on one's ideological leanings. The important point, which we made at the outset, is that from the perspective of researchers attempting to provide empirical data on adolescent decision making for policymakers, the debate about normative appeal of paternalistic policies is somewhat beside the point. For scientists, the study of adolescent decision making within a judgment framework makes sense because a poorly understood empirical issue is at the core of legal policies affecting minors, an issue that is currently the subject of considerable debate. The assumption that minors are developmentally inclined to use immature judgment is often explicitly invoked when courts endorse restrictive policies on such issues as adolescent abortion and 
psychiatric hospitalization ${ }^{4}$; it is discounted or disputed when policymakers are urged to expand adolescents' rights or to get tough on juvenile crime (Regnery, 1989). The debate about how adolescent decision making compares with that of adults mainly reflects ideology and intuition. In this politically charged environment, the task for researchers is to analyze the components of decision making that are relevant in different legal contexts, so as to provide policymakers with a more precise empirically based understanding of the ways in which the decision making of adolescents compares with that of adults.

\section{JUDGMENT AND ADOLESCENT DECISION MAKING}

In this section, we explore how the framework for comparing adolescent and adult decision making could be expanded beyond the constrictions imposed by informed consent doctrine to incorporate decision-making elements related to judgment. First, we sketch the three developmental factors that in some contexts may differentially affect decision making of adolescents and adults: (a) conformity and compliance in relation to peers and parents, (b) attitude toward and perception of risk, and (c) temporal perspective. We also suggest a few contextual factors that could affect decision making. Then, using a standard rational decision-making model, we analyze how these factors might influence decision making in ways that would not be captured by evaluation in an informed consent framework.

\section{Developmental Factors in Adolescence}

In general, adolescents are presumed to be less independent in their decision making than adults, and to be subject to the influence of both parents and peers.

\footnotetext{
${ }^{4}$ The United States Supreme Court has often described the immaturity of youthful judgment as the justification for parental authority and paternalistic oversight. For example, in the case Parham $v$. J. R. (1979),
}

Parents possess what children lack in maturity, experience and capacity for judgment required for making life's difficult decisions. ... Most children, even in adolescence, simply are not able to make sound judgments concerning many decisions, including their need for medical care or treatment. (p. 602)

And, in Bellotti v. Baird, (1979), the court wrote,

The court has held that the States validly may limit the freedom of children to choose for themselves in the making of important, affirmative choices with potentially serious consequences. These rulings have been grounded in the recognition that, during the formative years of childhood and adolescence, minors often lack the experience, perspective, and judgment to recognize and avoid choices that could be detrimental to them. (p. 635)

And, in Ginsburg v. New York, (1968),

Inexperience, less education, and less intelligence make the teenager less able to evaluate the consequences of his or her conduct. ... The difference that separates children from adults for most purposes of the law is children's immature, undeveloped ability to reason in an adultlike manner. (p. 649-650; Stewart, J., concurring) 
Salient developmental issues for adolescents include negotiating about power and control in the context of changing relationships with peers and parents (Allen, Aber, \& Leadbeater, 1990; Hill \& Holmbeck, 1986; Ryan \& Lynch, 1989; Steinberg \& Silverberg, 1986). Although, compared to younger children, adolescents have achieved greater autonomy in relation to their parents, tentative evidence suggests that they are more subject to parental influence than are young adults (Scherer, 1991; Scherer \& Reppucci, 1988). Although some believe that adolescents systematically reject parental influence and advice, research suggests parent orientation is context-dependent (Brittain, 1963; Larson, 1972). Some researchers have suggested that involvement in decision making can enhance compliance (Cromer \& Tarnowski, 1989; Taylor \& Adelman, 1986). The degree of successful involvement may depend in part on the quality and nature of the parentadolescent relationship, negative aspects of which have been related to adolescent problem behavior and parent-adolescent conflict (Allen et al., 1990; Eccles et al., 1991; Fuglini \& Eccles, 1993).

A more pressing concern for paternalists is that adolescents are believed to have a greater inclination to respond to peer influence than do adults (Berndt, 1979; Steinberg \& Silverberg, 1986). Peer influence appears to operate through two processes, social comparison and conformity. Through social comparison, adolescents use others' behavior as a measure of their own behavior (Sprinthall \& Collins, 1988). Social conformity, which appears to peak around age 15, leads adolescents to adapt their behavior and attitudes to those of their peers (Berndt, 1979; Coleman, 1974; Costanzo \& Shaw, 1966). Berndt (1979) found that peer conformity varies by age and target behavior. Conformity peaked in the ninth grade for situations involving antisocial behavior, but no age changes in peer influence on prosocial behavior were found. The importance of peer influence to adolescent decision making could be relevant in two ways. In some contexts, adolescents might be more vulnerable to direct peer pressure in making choices. More indirectly, adolescent desire for peer approval may affect decision making without any explicit coercion. For example, an adolescent may reject a particular outcome because she believes that her friends will disapprove. Comparisons to adults are difficult to make, however, because little research simultaneously examines peer influence on adolescents and adults.

Adolescents seem to differ from adults in their perception of and attitude toward risk (Finn \& Bragg, 1986; Gardner, 1992; Gardner \& Herman, 1991; Matthews \& Moran, 1986; Tester, Gardner, \& Wilfong, 1987). Adolescents and young adults take more risks with health and safety than do older adults, by more frequently engaging in activities such as criminal conduct, unprotected sex, and speeding. We are talking about the assessment of and attitude toward risk, not simply a lack of self control or impulsiveness. Different attitudes toward risk might result if adolescents are less risk averse than adults. It is unclear whether attitude toward risk remains constant across decision-making domains (Benthin, Slovic, \& Severson, 1993; Fischhoff, 1992). In some contexts, adolescent risk preferences may be linked to other developmental factors; for example, adolescents may be more averse than adults to risking social ostracism. Elkind (1967) suggests that adolescents conceptualize themselves as invulnerable to the poten- 
tially negative consequences of risk - a viewpoint consistent with legal paternalism. Quadrel, Fischhoff, and Davis's (1993) findings that low-risk teens', their parents', and high-risk teens' estimates of personal invulnerability were not greater for teens than for adults cast some doubt on Elkind's characterizations. However, their comparison fails to provide data about the accuracy of each groups' perception of its own level of vulnerability to particular risks. Thus, even though teenagers may perceive that they are as vulnerable (or more vulnerable) to unwanted pregnancy as are their mothers, this information does not tell us how accurately they perceive the actual level of risk they face.

Some differences have been demonstrated in other components of risk perception and attitudes. Compared to adults, adolescents appear to focus less on protection against losses than on opportunities for gains in making choices (Furby \& Beyth-Marom, 1990; Gardner et al., 1991). Adolescents appear to weigh the negative consequences of not engaging in risky behaviors more heavily than adults, although overall response patterns of adults and adolescents were quite similar (Beyth-Marom, Austin, Fischhoff, Palmgren, \& Quadrel, 1992). Differences in risk perception have also been observed. Research suggests that perception of risks increases through adolescence (perhaps with increased experience). Adolescents may sometimes be unaware of risks that adults perceive or they may calculate differently the probability or magnitude of a given risk (Furby \& BeythMarom, 1990; Kulbok, Earls \& Montgomery, 1988; Lewis, 1981; Phelps, 1987). For example, adolescents may be less willing than adults to risk disfiguring side effects of a medical treatment regimen due to concerns about body image and peer approval, but they may be more willing than adults to engage in behaviors such as bungee jumping.

Attitude toward risk is closely linked to differences in temporal perspective (Cottle, 1969; Greene, 1986; Grisso, 1981; Monks, 1968). In general, adolescents seem to discount the future more than adults and to weigh more heavily the short-term consequences of decisions - both risks and benefits - a response that in some settings contributes to risky behavior (Gardner \& Herman, 1991). Gardner and Herman (1991) hypothesize that this tendency may be linked to the greater uncertainty that young people may feel about their own futures, an uncertainty that might make short-term consequences seem more salient to an evaluation of different options (Allen, Leadbeater, \& Aber, 1990). It may also reflect the reality that adolescents have had less experience. It may be harder for an adolescent than for an adult to contemplate the meaning of a consequence that will be realized 10 to 15 years in the future, because such a time span is not easily made relevant to adolescent experience. Nurmi's (1991) review of the adolescent future orientation literature confirms that adolescents are most interested in major developmental tasks of late adolescence and early adulthood (i.e., career, education, marriage). Future planning skills grow more efficient with age but continue to develop at least into the early 20 's.

The importance of incorporating social and cultural context into an understanding of adolescent development has been underscored in Jessor's (1993) complex framework of adolescent risk behavior and ongoing research undertaken by the MacArthur Research Network on Adolescent Development among Youth in 
High Risk Settings. Several studies have suggested that factors such as socioeconomic status, race/ethnicity, and IQ tend to affect a variety of decision-making components, such as the meaning of "risk" and risky behavior, the number of opportunities to make decisions, the level of risk exposure, exposure and access to information, and degree of responsibility for decision-making consequences (Dake, 1991; Johnson, 1991; Jessor, 1993; Nurmi, 1991; Taylor \& Adelman, 1986). How these factors may combine with age is unclear and requires further study. Family structure and dynamics have been shown to affect adolescent participation in decision making (Dornbusch et al., 1985; Fuglini \& Eccles, 1993; Peterson, 1986; Smetana, 1988). Further, the larger cultural environment may constrain or enhance autonomy and decision-making opportunities. In general, the social and cultural contexts that shape adolescent experience may join with other developmental factors to affect decision making in a way that distinguishes among groups of adolescents or distinguishes adolescents from adults.

Although our brief literature review is by no means exhaustive, it does suggest that the three judgment factors warrant further investigation. Various literatures have described the developmental pathways of these factors and their possible relation to decision making. As such, further study may illuminate how they interact to affect decision making in legally relevant contexts for adolescents of different ages and adults. A framework for comparing the decision making of adolescents and adults that incorporates reasoning, understanding, judgment, and context factors will provide a richer and more contextual model for policyrelevant research. It provides a basis for examining decision-making processes and outcomes in order to explore whether systematic differences distinguish adults and adolescents.

\section{The Influence on Decision Making}

Developmental and contextual factors associated with adolescence could influence youthful decision making in at least two ways that would implicate judgment and that would not be captured by the informed consent framework. First, the factors could influence the way adolescents use information in making decisions. Second, adolescents, because of developmental influences, may attach different subjective value to consequences than adults; in this way, the costbenefit calculus and ultimately the decision outcome could be affected.

\section{The Use of Information}

The first stages of decision making involve the gathering and organization of information. Adolescents could differ from adults in considering different or fewer options in thinking about their available choices, or in identifying different consequences when evaluating and comparing alternatives (Furby \& Beyth-Marom, 1990). Younger decision makers may differ from adults in their knowledge of relevant information or in the amount and type of information that they actually use in making a decision. Adults and adolescents also might sometimes vary in 
their response to the source of information as a determinant of its use (Fischhoff, 1992; Lewis, 1981).

The research on how adolescents and adults compare in their use of information has produced ambiguous results. Adolescents are similar to adults in their cognitive capacity for information processing (Gardner et al., 1989) and, in some contexts, are also similar to adults in the use of information that is provided to them (Quadrel et al., 1993; Weithorn \& Campbell, 1982). Research findings do indicate that, in some contexts, adolescents making decisions use and are aware of less information than adults, and particularly information about risk (Gardner et al., 1991; Lewis, 1981; Tester et al., 1987). Taken together, these studies indicate that, in some contexts, adolescents may differ from adults in the way they use information in making choices. However, few generalizations seem to hold and the sources of difference are quite complex; dissimilar attitude toward and perception of risk, experience, and knowledge may all be interwoven.

When decision making is formally evaluated under an informed consent framework, all relevant information is disclosed, and deficiencies in the use of information will be apparent only if relevant information is disregarded. It is in informal, less structured settings that ignorance about salient information may affect judgment in the making of choices, even though the decision is made through a rational process. For example, the decision to drive after several drinks might reflect ignorance about the effect of alcohol. A disparity between adults and minors of this kind would be of interest when it translates into decisions that threaten significant harm to the youthful decision maker or to others. ${ }^{5}$ For policy purposes, it seems important to know a lot more than we do about how adolescents compare with adults in their use of information in contexts in which they must draw on their own experience.

\section{Value Differences}

Research evidence supports the view that youthful decision makers, because of developmental influences, sometimes differ from adults in the subjective value that they attach to various perceived consequences in the process of making choices (Furby \& Beyth-Marom, 1990; Gardner \& Herman, 1991; Gardner, 1992; Kulbok et al., 1988). In undertaking a cost-benefit calculus, minors might weigh a particular cost or benefit differently from adults (or view as a benefit what adults would count as a cost) (Benthin et al., 1993; Hampson, Burns, Severson, \& Slovic, 1992; Lavery, Siegel, Cousins, \& Rubovits, 1992). For example, if adolescents care more about personal appearance and peer approval than adults, and differ in temporal perspective, an adolescent more readily than an adult might reject a treatment (for example, a brace for scoliosis) that offers a long-term benefit but short-term embarrassment. Medical research has provided some evi-

\footnotetext{
${ }^{5}$ As Richard Bonnie (personal communication, 1992) has pointed out, this deficiency amounts, in part, to a lack of foresight, and thus can be seen as analogous to negligence. Decision makers might be described as negligent if they do not foresee consequences that the ordinary decision maker would foresee. If this is true of adolescents in some contexts, we would not attach the culpability that negligence connotes, but we might conclude that they are "developmentally negligent."
} 
dence regarding adolescent concern with body image and treatment regimens (Cromer \& Tarnowski, 1989; Korsch, Fine, \& Negrete, 1978; Weithorn \& Campbell, 1982), but it is unclear whether the extent of this concern exceeds that of adults.

Adolescents and adults might also calculate dissimilarly the probability of a given risk. Adolescents are more likely than adults to engage in risky behavior, perhaps because it seems less risky to them than to adults. ${ }^{6}$ In part, this may be due to differences in information access, but it could also involve dissimilar attitudes toward risk and different temporal perspectives. For example, an adolescent's choice to hold up a convenience store with his friends might reflect a risk-preferring attitude and a tendency to give relatively more weight to short-term consequences (and less to long-term consequences) than would an adult. In another context, adolescents and adults might both think sexual experimentation poses a risk of pregnancy and AIDS. However, the two groups may assess differently the probability that the negative consequences will occur, or, due to dissimilar risk preferences, differ on whether a risk of a given magnitude is prohibitive or acceptable (Bauman \& Udry, 1981; Zabin, Kanter, \& Ford, 1980).

It would be irrelevant in assessing competence under an informed consent framework that adults and minors attach different values to particular consequences and reach different outcomes. The risk-benefit calculus explicitly measures subjective utility, the value to the decision maker of the potential consequences of each option. A rational decision maker makes the choice that best promotes her personal values. The outcome is not measured against any external standard for reasonableness; what might seem like an onerous cost of a particular option to one person could appear trivial to another. ${ }^{7}$

Social scientists who study decision making also tend to agree that these kinds of differences are not legitimate or useful measures. The study of adolescent risk-taking behavior by Furby and Beyth-Marom (1990) provides a clear illustration. These psychologists consider, from a decision-making perspective, risky activities that teens engage in more commonly than adults: sex without contraceptives, reckless driving, and health-threatening use of drugs and alcohol. The

\footnotetext{
${ }^{6}$ For some activities relying on physical characteristics such as strength, endurance, and agility, adolescents may be correct - they may be better equipped than adults. Even with rigorous physical activities, however, there may be factors other than physical ability that are necessary to risk assessment.

${ }^{7}$ Consider, for example, a young woman deciding whether or not to consent to a leg amputation for cancer. Assume that her chances for long-term survival are $90 \%$ if she consents. If she refuses, her condition is terminal; she will live at most three or four years. In this situation, a rational decision maker could calculate that the cost associated with the loss of her leg (the long hospitalization, the resulting impairment to her appearance and mobility, and the anticipated impairment to her social relationships) outweigh the benefit of long-term survival with one leg. If most people would reach a different outcome, this says only that most people subjectively attach different values than does this decision maker to long-term survival, on the one hand, and to hospitalization, personal appearance, mobility, and/or peer relations on the other. The point is that, if the individual evaluates options and their consequences, and engages in a cost-benefit calculus of the type described above, the decisionmaking process is rational and, by standard measures, competent, even if the outcome is determined by idiosyncratic values or preferences.
} 
authors argue persuasively that the adolescent who engages in risk-taking behavior is not necessarily an irrational sensation seeker who miscalculates risk. Instead, she might well be rationally choosing the option that maximizes her subjective utility, and which therefore holds less risk of loss and more potential gain than the alternative choices. Since loss and gain are defined according to the decision maker's own values, conduct could well appear unacceptably risky to adults but not to adolescents. Thus a teen, deciding whether to accept an invitation to join her friends in taking drugs, might conclude that the costs of saying "no," in terms of self image (who wants to be a geek?) and peer rejection, weigh more heavily than the risk of addiction or apprehension, and that the benefit of feeling good and sharing in the group experience is greater than that of being a clear-headed law-abiding citizen. Saying "yes" under these circumstances is simply the rational cost-avoiding choice and not risky behavior at all.

This analysis demonstrates the problem (if data useful to policymakers is the goal) with thinking about adolescent legal competence in the constricted framework in which adult decision making is studied and evaluated. Scientists studying decision making are appropriately reluctant to get involved in the business of subjecting the values that shape the decision-making calculus to an "objective" normative standard. This neutrality does not, by and large, characterize the response of policymakers, who are quite ready to conclude that adolescent choices that are health threatening or life threatening, or that restrict future opportunity, are risky choices that reflect poor judgment, even if they rationally promote the decision maker's values at the time the decision is made. Moreover, if the values that drive risky choices are associated with youth, and predictably will change with maturity, then the paternalistic inclination is to protect the young decision maker - and society - from the outcome of his bad judgment. This impulse is not quelled by the knowledge that, in making the "poor" decision, the youthful decision maker has engaged in a rational process.

\section{ADOLESCENT JUDGMENT: THE IMPLICATIONS FOR RESEARCH}

Expanding our understanding of decision-making competence from the restricted framework of the informed consent model to one that encompasses judgment requires expansion of the scope of empirical investigation of how adolescent decision making compares with that of adults. A richer understanding of the decision-making capabilities of children and adolescents relative to adults will entail both recognizing the importance of research findings that have not seemed relevant under the informed consent framework and pursuing a broader program of policy-relevant research.

In this section, we take the first step in conceptualizing judgment research. We present three legally relevant contexts for research: (a) medical treatment, including both reproductive choices (contraception and abortion) and long-term or chronic illness treatment; (b) mental health treatment; and (c) delinquent and/or criminal behavior. We describe why these contexts present useful settings to 
evaluate decision making of adolescents and adults using the expanded judgment framework, and how each of the judgment factors may differ between the two groups. We conclude with a brief discussion of methodological concerns.

\section{Decision-Making Contexts}

\section{Medical Treatment}

Advocates of expanded adolescent rights argue that adolescents should have general authority to make medical decisions free of parental involvement. Research on decisions about abortion and contraception use as well as decisions about treatment of chronic illness can usefully clarify how adolescents and adults approach health care choices.

The issue of adolescents' independent access to abortion and contraception has been an important focus of policy debate. In many states, parental consent or notification laws require that parents be informed of a minor's intent to obtain an abortion before it can be performed. ${ }^{8}$ Courts endorsing requirements of parental involvement have justified restrictions as necessary because of immature adolescent judgment (Bellotti v. Baird, 1979; H.B. v. Wilkinson, 1986). Contraceptives by prescription are more readily available, often through statutes that authorize minors to consent to treatment without involving their parents. However, an adolescent's legal authority in this area is uncertain in many states. Issues of decision-making capability are relevant to independent access to these treatments.

Greater understanding of the ways in which adolescents and adults decide to engage in protected (and unprotected) sexual activity is of policy importance, because of the substantial social costs of unprotected sexual activity, such as unplanned pregnancy and sexually transmitted disease, particularly HIV. The three judgment factors may well differentiate adolescent and adult decision making in these contexts. Adolescents may anticipate a negative reaction of peers and parents to contraceptive use. The adolescent peer culture may view contraceptives as interfering with sexual pleasure or, for girls, as an open acknowledgement of 'readiness' for sexual activity (Flaherty, Marecek, Olsen, \& Wilcove, 1983). Contraceptive use would be evidence of sexual activity to parents, who presumably prefer that their adolescents abstain. Adults and adolescents may perceive the risk of pregnancy or disease contraction from unprotected sex differently. Shaklee and Fischhoff (1990) have documented adults' inaccurate risk perceptions of long-term contraceptive effectiveness, but similar research on adolescents has not yet been conducted. Moreover, adolescents and adults may value differently

\footnotetext{
${ }^{8}$ Several Supreme Court cases have addressed parental notification and parental consent. For parental notification, see H. L. v. Matheson (1981), Webster v. Reproductive Health Services (U.S. July 3, 1989), Hodgson v. Minnesota (U.S. July 26, 1990), Ohio v. Akron Center for Reproductive Health, (U.S. June 26, 1990). For parental consent, see Planned Parenthood of Central Missouri v. Danforth (1976), Bellotti v. Baird (1979), City of Akron v. Akron Center for Reproductive Health (1983), Planned Parenthood of Kansas City, Missouri v. Ashcroft (1983), Thornburgh v. American College of Obstetricians and Gynecologists (1968). For a discussion of the impact of these cases on adolescent access to abortion, see Crosby and Reppucci (1993).
} 
the long-term consequences of pregnancy or disease in comparison to the shortterm gains of a sexual encounter.

Decisions regarding treatment for chronic illness constitute a second context in which health care decision making could be explored. In this setting, patients face a number of choices regarding available interventions. The medical literature has examined adolescents with respect to renal transplant, diabetes, and cancer treatment regimens, suggesting that they are at risk for making poor health care decisions because of noncompliant behavior. Painful or negative side effects were related to lower adolescent compliance rates for renal transplants (Korsch et al., 1978) and cancer treatment (Dolgin, Katzer, \& Doctors, 1986), but not for healthy adolescents using oral contraceptives (Neel, Litt, \& Jay, 1987). While there are data to suggest that adolescents are less compliant with medical treatment than younger children (Cromer \& Tarnowski, 1989), a widespread belief that they are also less compliant than adults remains unsubstantiated, because studies do not directly compare adolescents and adults. Compliance rates across studies of adolescents appear comparable to those found in studies of adults (Appelbaum \& Hoge, 1986; Cromer \& Tarnowski, 1989). These similarities are found largely in studies of patients in long-term medical regimens, but appear to hold true for behavioral regimens (wearing glasses, following a diet, wearing a brace) as well (Cromer \& Tarnowski, 1989). By examining judgment factors, ${ }^{9}$ it would be possible to determine whether adolescents in fact do make poorer decisions than adults and if similar factors influence their decisions. Moreover, research could test the hypothesis that greater participation by adolescents in treatment decisions contributes to greater compliance. If validated, this might have interesting implications for legal reform.

\section{Mental Health Treatment}

A related area of decision making that has also been the subject of legal policy attention involves inpatient and outpatient mental health treatment. In Parham v. $J . R$. (1979), the Supreme Court recognized that individual liberty and privacy interests are implicated in the psychiatric hospitalization of minors, but held that parents can admit their children involuntarily to mental hospitals if a staff physician agrees with the need for treatment. In upholding the constitutionality of parental admissions, the Court emphasized the immature judgment and lack of experience of minors. However, many states impose procedural restrictions on

\footnotetext{
${ }^{9}$ One of the most popular medical models for studying compliance is the Health Belief Model (Janz \& Becker, 1984). The four factors determining compliance, which map onto our judgment factors rather well, include (1) perceived sušceptibility to disease, corresponding to risk perception; (2) perceived severity of condition, corresponding to temporal perspective and risk perception; (3) perceived benefits of treatment regimen, corresponding to temporal perspective; and (4) perceived barriers to following recommended treatment, which can include negative physical side effects (physical attractiveness) and changes in lifestyle (peer conformity). The patient's perceived susceptibility to disease is important, but by far the most powerful predictor is the calculation of possible benefits against the perceived "cost" of adherence.
} 
parental authority, recognizing that minors may have an independent-and conflicting-interest in the decision.

The issue of noncompliance becomes salient in this context. As the use of psychotropic drugs such as antidepressants has become more commonplace and their side effects better known, some patients prefer not to take them. Initial studies indicate that pharmacotherapy may not be an effective approach for treatment of adolescent depression (Petersen et al., 1993). Moreover, patients sometimes object to recommended psychiatric hospitalization. It is important to determine whether adolescent choices not to comply with recommended treatments are comparable to those of adults or whether youthful rebellion plays a role. Research can clarify whether adults and adolescents evaluate the short-term consequences of freedom (staying out of the hospital) versus the long-term benefits of treatment differently. Research could also examine the concerns about peer reaction to medication or psychiatric hospitalization.

\section{Criminal and Delinquent Conduct}

Although the prevention and treatment of juvenile delinquency have been researched and debated for decades, recent increases in serious juvenile crime have galvanized national debate on juveniles' rights and responsibilities. Federal and state policymakers have responded to public outcry with legislation facilitating and/or mandating the transfer of juveniles accused of serious and/or violent crimes to adult criminal court and the implementation of stiffer sentences (Bishop, Frazier, \& Henretta, 1989; Champion, 1989; Poulos \& Orchowsky, 1994; Sanborn, 1994). In part, these changes reflect a trend toward deterrence and retribution in the entire criminal justice system; however, they are counter to a basic premise of the juvenile justice system, viz. that minors, because their criminal conduct reflects immaturity, not be held to adult standards of criminal responsibility. The use of mandatory transfer and "adultlike" sentencing of juveniles also means that individualized justice with a focus on rehabilitation, the cornerstone of the juvenile justice system, has virtually been eliminated. For example, even Virginia, the only state in which it is explicitly stated that a juvenile cannot be transferred unless the youth is found competent, has recently enacted legislation that not only expands the kinds of crimes for which juveniles may be transferred without an amenability to treatment determination (Mulvey, 1984; Mulvey \& Reppucci, 1988), but directs that, once a juvenile has been transferred to criminal court for any offense, all subsequent offenses will be tried in criminal court-in essence, the juvenile court will no longer retain jurisdiction (Va Code \$16.1-271).

Assumptions about adolescents' cognitive capacities, attitudinal frameworks, and amenability to treatment are grounded largely in anecdotal data and practical experience. With the exception of Grisso's (1981) study of adolescents' understanding of Miranda waivers, no research has examined differences between adolescent and adult decision making regarding any issue related to criminal conduct or proceedings. Empirical research developed in the judgment framework can clarify how relevant factors influence juveniles' decisions to engage in criminal behavior and their subsequent interactions with the justice system. For example, 
adolescents may not appreciate the long-term consequences or potentially serious ramifications of criminal conduct for themselves and others. Adolescents and adults may perceive differently the risks and benefits of both engaging in criminal behavior and being held legally responsible for such behavior. Further, the increasing numbers and influence of juvenile gangs, which are often characterized as "substitute families" (Huff, 1989; Thompson \& Jason, 1988), suggest that peer influence may be especially relevant.

\section{Methodology}

The discussion of judgment factors and decision-making contexts raises a number of methodological considerations, which we review briefly. Although with few exceptions the legal system treats persons under age 18 (and for some activities age 21) as incompetent, research should not assume that adolescents are a homogenous group unless scientific evidence warrants such a conclusion. Indeed, variation within the adolescent group may exceed the differences between adolescents and adults. Demographic and cultural characteristics may differentiate adolescents depending on the decision-making context. The importance of context-specific research cannot be overestimated: Competencies may not be generalizable across situations.

Other methodological factors warrant attention. Research in both naturalistic and laboratory settings is necessary to provide a comprehensive account of the relevant comparisons. Although laboratory settings provide greater control and facilitate the study of many different groups of adolescents, more naturalistic settings may provide a closer approximation of the "true" relationship between judgment and decision making in the legally relevant context. Further, prior research suggests that on judgment-related issues such as risk perception (Lewis, 1980), risk preference (Gardner, 1992), and susceptibility to peer conformity (Costanzo \& Shaw, 1966), performance (as measured by adult standards) improves with age. These findings highlight the necessity of studying decision-making performance from early adolescence through adulthood. Longitudinal studies could shed light on how judgment factors change throughout development, providing information in intraindividual change as well as interindividual differences in intraindividual change. Comparison with adult groups is critical to exploring differences. The comparison of relationships between judgment factors across time, whether cross-sectionally or longitudinally, will facilitate a more comprehensive understanding of development.

Given the complex nature of judgment factors and the decisions they may influence, multiple measures must be chosen to represent adequately each judgment factor's theoretical domain. Decisions must be conceptualized as choices between alternate behaviors, and consequences must include the impact of not engaging in a behavior, such as choosing not to smoke when everyone else is (Beyth-Marom et al., 1992; Fischhoff, 1993). The positive and negative consequences of choosing not to smoke may not be the same as those of choosing to smoke.

A judgment framework for research on adolescent decision making can pro- 
vide the basis for empirical study that focuses on legally relevant contexts. The interrelationship of informed consent, judgment, and contextual factors will provide a more useful, although more complex, account of decision making than the informed consent framework currently provides.

\section{THE JUDGMENT FRAMEWORK AND LEGAL POLICY}

The task of science is to chart the similarities and differences in adolescent and adult decision making. The task of policymakers is to decide about appropriate legal responses. Currently, the intuitions about adolescent immaturity that have supported paternalistic legal responses are being challenged by critics across the political spectrum. Whether paternalism is appropriate depends in part on empirical issues that currently are unsettled. If research findings indicate that the differences between adolescents and adults are less than we supposed, then the burden to justify restrictive policies directed toward minors becomes greater. On the other hand, evidence of youthful immaturity may bolster special protections for minors. In light of the Supreme Court's endorsement of extension of the death penalty to 16- and 17-year-olds (Stanford v. Kentucky, 1989), a solid empirical understanding of adolescent maturity is critical.

A more comprehensive understanding of adolescent decision making can facilitate policies that are tailored to the exigencies of adolescence and suggest legal strategies that respond to developmental difference. For example, if adolescents, indeed, are less compliant with medical treatment than are adults, it may be due to conflict around dependency associated with illness. If this is so, then it seems unhelpful to interpret the evidence as justification for restriction. Instead, the better response might be to encourage responsibility in adolescent patients through consultation and participation in the decision making.

It is clear that no simplistic formula defines the relationship between adolescent decision-making capability and policies of restriction, protection, and selfdetermination. Adolescents (or some adolescents) may be indistinguishable from adults in approaching a particular choice, and yet extending legal authority may appear to carry too high a cost in terms of administration, enforcement, or family disruption, with too little benefit to the minor. Moreover, the political cost of extending freedom may be an inclination to withdraw special protections from youth. Policy choices will be driven by distinctive formulas based on many variables of which competence is only one. Nonetheless, to the extent that presumptions about adolescent decision-making capability are important in shaping policy, those presumptions are more usefully based on data than on intuition and ideology.

\section{REFERENCES}

Allen, J. P., Aber, J. L, \& Leadbeater, B. J. (1990). Adolescent problem behaviors: The influence of attachment and autonomy. Psychiatric Clinics of North America, 13, 455-467. 
Allen, J. P., Leadbeater, B. J., \& Aber, J. L. (1990). The relationship of adolescents' expectations and values to delinquency, hard drug use, and unprotected sexual intercourse. Development and Psychopathology, 2, 85-98.

Ambuel, B., \& Rappaport, J. (1992). Developmental trends in adolescents' psychological and legal competence to consent to abortion. Law and Human Behavior, 16, 129-154.

Appelbaum, P. S. (1987). Informed consent: Legal theory and clinical practice. New York: Oxford University Press.

Appelbaum, P. S., \& Grisso, T. (1988). Assessing patients' capacities to consent to treatment. New England Journal of Medicine, 319, 1635-1638.

Appelbaum, P. S., \& Hoge, S. K. (1986). The right to refuse treatment: What the research reveals. Behavioral Sciences and the Law, 4, 279-292.

Bauman, K. E., \& Udry, J. R. (1981). Subjective expected utility and adolescent sexual behavior. Adolescence, 16, 527-535.

Bellotti v. Baird, 443 U.S. 622 (1979).

Belter, R. W., \& Grisso, T. (1984). Children's recognition of rights violations in counseling. Professional Psychology: Research and Practice, 15, 899-910.

Benthin, A. C., Slovic, P., \& Severson, H. (1993). A psychometric study of adolescent risk perception. Journal of adolescence, 16, 153-168.

Berndt, T. J. (1979). Developmental changes in conformity to peers and parents. Developmental Psychology, 15, 608-616.

Beyth-Marom, R., Austin, L, Fischoff, B., Palmgren, C., \& Quadrel, M. J. (1992). Perceived consequences of risky behaviors: Adults and adolescents. Developmental Psychology, 29, 549-563.

Bishop, D. M., Frazier, C. E., \& Henretta, J. C. (1989). Prosecutorial waiver: Case study of a questionable reform. Crime and Delinquency, 35, 179-201.

Brittain, C. V. (1963). Adolescent choices and parent-peer cross-pressures. American Sociological Review, 28, 385-391.

Champion, D. J. (1989). Teenage felons and waiver hearings: Some recent trends, 1980-1988. Crime and Delinquency, 35, 577-585.

Chassin, L., Presson, C. C., Sherman, S. J., \& Edwards, D. A. (1991). Four pathways to young-adult smoking status: Adolescent social-psychological antecedents in a midwestern community sample. Health Psychology, 10, 409-418.

City of Akron v. Akron Center for Reproductive Health, 462 U.S. 416 (1983).

Coleman, J. S. (1961). The adolescent society. New York: The Free Press.

$\rightarrow$ Costanzo, P. R., \& Shaw, M. E. (1966). Conformity as a function of age level. Child Development, 37, 967-975.

Cottle, T. J., Howard, P., \& Pleck, J. (1969). Adolescent perceptions of time: The effect of age, sex and social class. Personality, 37, 636-650.

Cromer, B. A., \& Tarnowski, K. J. (1989). Noncompliance in adolescents: A review. Developmental and Behavioral Pediatrics, 10, 207-215.

Crosby, C., \& Reppucci, N. D. (1993). The legal system and adolescents. In P. Tolan and B. Cohler (Eds.), Handbook of clinical research and practice with adolescents (pp. 281-304). New York: Wiley.

Dake, K. (1991). Orienting dispositions in the perception of risk. Journal of Cross Cultural Psychology, 22, 61-82.

Dolgin, M. H., Katzer, S., \& Doctors, S. R. (1986). Caregivers' perceptions of medical compliance in adolescents with cancer. Journal of Adolescent Health Care, 7, 22-27.

$\rightarrow$ Dornbusch, S. M., Carlsmith, J. M., Bushwall, S. J., Ritter, P. L., Leiderman, H., Hastorf, A. H., \& Gross, R. T. (1985). Single parents, extended households, and the control of adolescents. Child Development, 56, 326-341.

Dowie, M. (1993). Tough justice: When kids commit adult crimes, some say they should do adult time. California Lawyer, 13, 54-58, 119.

Eccles, J. S., Buchanan, C. M., Flanagan, C., Fuligni, A., Midgley, C., \& Yee, D. (1991). Control versus autonomy during early adolescence. Journal of Social Issues, 47, 53-68.

Eccles, J. S., Midgley, C., Wigfield, A., Buchanan, C. M., Reuman, D., Flanangan, C., \& MacIver, 
D. (1993). Development during adolescence: The impact of stage-environment fit on young adolescents' experiences in schools and families. American Psychologist, 48, 90-101.

$\rightarrow$ Elkind, D. (1967). Egocentrism in adolescence. Child Development, 38, 1025-1034.

Finn, P., \& Bragg, B. W. E. (1986). Perception of the risk of an accident by young and older drivers. Accident Analysis and Prevention, 18, 289-298.

Fischer, K. W., \& Silvern, L. (1985). Stages and individual differences in cognitive development. Annual Review of Psychology, 36, 613-648.

Fischhoff, B. (1992). Risk taking: A developmental perspective. In J. F. Yates (Ed.), Risk-taking behavior (pp. 133-162). New York: Wiley.

Fischhoff, B., \& Quadrel, M. J. (1991). Adolescent alcohol decisions. Alcohol Health and Research World, 15, 43-51.

Flaherty, E. W., Marecek, J., Olsen, K., \& Wilcove, G. (1983). Preventing adolescent pregnancy: An interpersonal problem solving approach. Prevention in Human Services, 2, 49-64.

Flavell, J. H. (1985). Cognitive development. Englewood Cliffs, NJ: Prentice Hall.

Fuligni, A. J., \& Eccles, J. S. (1993). Perceived parent-child relationships and early adolescents' orientation toward peers. Developmental Psychology, 29, 622-632.

Furby, L., \& Beyth-Marom, R. (1992). Risk-taking in adolescence: A decision-making perspective. Development Review, 12, 1-44.

Gardner, W. (1992). A life span theory of risk taking. In N. Bell (Ed.), Adolescent and adult risk taking: The eighth Texas Tech symposium on interfaces in psychology. Newbury Park: Sage.

Gardner, W., \& Herman, J. (1991). Adolescents' AIDS risk taking: A rational choice perspective. In W. Gardner, S. Millstein, \& B. Wilcox (Eds.), Adolescents in the AIDS epidemic (pp. 17-34). San Francisco: Jossey-Bass.

Gardner, W., Herman, J., \& Wilfong, E. (1991). Developmental change in decision making. Unpublished manuscript.

Gardner, W., Scherer, D., \& Tester, M. (1989). Asserting scientific authority: Cognitive development and adolescent legal rights. American Psychologist, 44, 895-902.

Garrison, E. (1991). Children's competence to participate in divorce custody decisions. Journal of Clinical Child Psychology, 20, 78-87.

Ginzberg v. New York, 390 U.S. 629 (1968).

Gittler, J., Quigley-Rick, M. \& Saks, M. (1990) Adolescent health care decision making: The law and public policy. Carnegie Council on Adolescent Development, Washington, DC.

Greene, A. L. (1986). Future-time perspective in adolescence: The present of things future revisited. Journal of Youth and Adolescence, 15, 99-113.

$\rightarrow$ Grisso, T. (1980). Juveniles' capacities to waive Miranda rights: An empirical analysis. California Law Review, 68, 1134-1166.

Grisso, T. (1981). Juveniles' waiver of rights: Legal and psychological competence. New York: Plenum.

Grisso, T., \& Appelbaum, P. (1992). Manual for Understanding Treatment Disclosures. (Unpublished manuscript).

Grisso, T., \& Vierling, L. (1978). Minors' consent to treatment: A developmental perspective. Professional Psychology: Research and Practice, 9, 421-427.

Gudjonsson, G. H., \& Singh, K. K. (1984). Interrogative suggestibility and delinquent boys: An empirical validation study. Personality and Individual Differences, 5, 425-430.

H. B. v. Wilkinson, 639 F. Supp. 952 (D. Utah 1986).

H. L. v. Matheson, 450 U.S. 398 (1981).

Hampson, S. E., Burns, W. J., Severson, H. H., \& Slovic, P. (1992). Adolescent alcohol-related risk taking: Exploring structural relations among risk perceptions, personality, and risk taking. Unpublished manuscript.

Hartigan v. Zbaraz, Brief of Amicus curiae, American Psychological Association, in support of appellees, Zbaraz v. Hartigan, 484 U.S. 171 (1987) (No. 85-673).

Hill, J. P., \& Holmbeck, G. N. (1986). Attachment and autonomy during adolescence. Annals of Child Development, 3, 145-189.

Hodgson v. Minnesota, 58 U.S.L.W. 4957 (U.S. July 26, 1990).

Huff, R. C. (1989). Youth gangs and public policy. Crime and Delinquency, 35, 524-537. 
Inhelder, B., \& Piaget, J. (1958). The growth of logical thinking from childhood to adolescence. New York: Basic.

Janz, N. \& Becker, M. (1984). The health belief model: A decade later. Health Education Quarterly, $11,1-47$.

Jessor, R. (1993). Successful adolescent development among youth in high-risk settings. American Psychologist, 48, 117-126.

Johnson, B. B. (1991). Risk and culture research-Some cautions. Journal of Cross Cultural Research, 22, 141-149.

Kahneman, D., Slovic, P., \& Tversky, A. (Eds.) (1982). Judgment under uncertainty: Heuristics and biases. New York: Cambridge University Press.

Kaser-Boyd, N., Adelman, H. S., \& Taylor, L. (1985). Minors' ability to identify risks and benefits of therapy. Professional Psychology: Research and Practice, 16, 411-417.

Kaser-Boyd, N., Adelman, H. S., Taylor, L., \& Nelson, P. (1986). Children's understanding of risks and benefits of psychotherapy. Clinical Child Psychology, 15, 165-171.

Katz, J., \& Capron, A. (1975). Catastrophic diseases: Who decides what? New York: Russell Sage.

Korsch, B. M., Fine, R. N., \& Negrete, V. F. (1978). Noncompliance in children with renal transplants. Pediatrics, 61, 872-876.

Kulbok, P. P., Earls, F. J., \& Montgomery, A. C. (1988). Life style and patterns of health and social behavior in high-risk adolescents. Advances in Nursing Science, 11, 22-35.

Larson, L. E. (1972). The influence of parents and peers during adolescence: The situation hypothesis revisited. Journal of Marriage and the Family, 34, 67-74.

Lavery, B., Siegel, A. W., Cousins, J. H., \& Rubovits, D. S. (1993). Adolescent risk-taking: An analysis of problem behaviors in problem children. Journal of Experimental Child Psychology, 55, 277-294.

Lee v. Weisman, 112 S. Ct 2649 (1992).

Lewis, C. C. (1981). How adolescents approach decisions: Changes over grades seven to twelve and policy implications. Child Development, 52, 538-544.

Lewis, C. C. (1980). A comparison of minors' and adults' pregnancy decisions. American Journal of Orthopsychiatry, 50, 446-453.

Matthews, M. L., \& Moran, A. R. (1986). Age differences in male drivers' perception of accident risk: The role of perceived driving ability. Accident Analysis and Prevention, 18, 299-313.

Meisel, A. (1979). The "exceptions" to the informed consent doctrine: Striking a balance between competing values in medical decision making. Wisconsin Law Review, 1979, 413-488.

Melton, G. B. (1983a). Child advocacy: Psychological issues and intervention. New York: Plenum.

Melton, G. B. (1983b). Toward "presonhood" for adolescents: Autonomy and privacy as values in public policy. American Psychologist, 38, 99-103.

Monks, F. (1968). Future time perspective in adolescence. Human Development, 11, 107-123.

Moseley-Braun, C. (1994, March). Yes: Send a message to young criminals. American Bar Association Journal, 80, 46.

Mulvey, E. P. (1984). Judging amenability to treatment in juvenile offenders. In N. D. Reppucci, L. A. Weithorn, E. P. Mulvey, \& J. Monahan (Eds.), Children, mental health and the law (pp. 195-210). Beverly Hills, CA: Sage.

Mulvey, E. P., \& Reppucci, N. D. (1988). The context of clinical judgment: The effect of resource availability on judgments of amenability to treatment in juvenile offenders. American Journal of Community Psychology, 16, 525-546.

Neel, E. U., Litt, I. F., \& Jay, M. S. (1987). Side effects and compliance with low- and conventionaldose oral contraceptive among adolescents. Journal of Adolescent Health Care, 8, 327-329.

Nurmi, J. (1991). How do adolescents see their future? A review of the development of future orientation and planning. Developmental Review, 11, 1-59.

Ohio v. Akron Center for Reproductive Health, 58 U.S.L.W. 4979 (U.S. June 26, 1990).

Parham v. J. R., 422 U.S. 584 (1979).

Petersen, A. C., Compas, B. E., Brooks-Gunn, J., Stemmler, M., Ey, S., \& Grant, K. E. (1993). Depression in adolescence. American Psychologist, 48, 155-168.

Petersen, G. W. (1986). Parent-youth power dimensions and the behavioral autonomy of adolescents. Journal of Adolescent Research, 1, 231-249. 
$\rightarrow$ Phelps, C. E. (1987). Risk and perceived risk of drunk driving among young drivers. Journal of Policy Analysis and Management, 6, 708-714.

Planned Parenthood of Central Missouri v. Danforth, 428 U.S. 52 (1976).

Planned Parenthood of Kansas City, Missouri v. Ashcroft, 462 U.S. 476 (1983).

Poulos, T. M., \& Orchowsky, S. (1994). Serious juvenile offenders: Predicting the probability of transfer to criminal court. Crime and Delinquency, 40, 3-17.

President's Commission for the Study of Ethical Problems in Medicine and Biomedical and Behavioral Research. (1982). Making Health Care Decisions, Vol. 1. Washington, DC.

Quadrel, M. J., Fischhoff, B., \& Davis, W. (1993). Adolescent (in) vulnerability. American Psychologist, 48, 102-116.

Regnery, A. S. (1989). Getting away with murder. Policy Review, 34, 65-69.

Roth, L. H., Meisel, A., \& Lidz, C. W. (1977). Tests of competency to consent to treatment. American Journal of Psychiatry, 134, 279-284.

$\rightarrow$ Ryan, R. M., \& Lynch, J. H. (1989). Emotional autonomy versus detachment: Revisiting the vicissitudes of adolescence and young adulthood. Child Development, 60, 340-356.

Sanborn, J. B. (1994). Certification to criminal court: The important policy questions of how, when, and why. Crime and Delinquency, 40, 262-281.

Scherer, D. G. (1991). The capacities of minors to exercise voluntariness in medical treatment decisions. Law and Human Behavior, 15, 431-449.

Scherer, D. G., \& Reppucci, N. D. (1988). Adolescents' capacities to provide voluntary informed consent: The effect of parental influence and medical dilemmas. Law and Human Behavior, 12, 123-141.

Scott, E. (1992). Judgment and reasoning in adolescent decision making. Vanderbilt Law Review, 37, 1607-1669.

$\rightarrow$ Scott, E. (1990). Rational decision making about marriage and divorce. Virginia Law Review, 76, 9-94.

Scott, E., Reppucci, N. D., \& Aber, M. (1988). The role of the child's preference in custody proceedings. Georgia Law Review, 22, 1035-1078.

Seigler, R. S. (1991). Children's thinking (2nd ed.). Englewood Cliffs, NJ: Prentice-Hall.

Shaklee, H. (1979). Bounded rationality and cognitive development: Upper limits on growth? Cognitive Psychology, 11, 327-345.

Shaklee, H., \& Fischhoff, B. (1990). The psychology of contraceptive surprise: Cumulative risk and contraceptive effectiveness. Journal of Applied Social Psychology, 20, 385-403.

$\rightarrow$ Smetana, J. G. (1988). Adolescents' and parents' conceptions of parental authority. Child Development, 59, 321-335.

Sprinthall, N., \& Collins, W. A. (1988). Adolescent psychology: A developmental view. New York: Random House.

Stanford v. Kentucky, 109 S. Ct. 2969 (1989).

$\rightarrow$ Steinberg, L., \& Silverberg, S. B. (1986). The vicissitudes of autonomy in early adolescence. Child Development, 57, 841-851.

Taylor, L., \& Adelman, H. S. (1986). Facilitating children's participation in decisions that affect them: From concept to practice. Journal of Clinical Child Psychology, 15, 346-351.

Tester, M., Gardner, W., \& Wilfong, E. (1987, August). Experimental studies of the development of decision-making competence. In Children, risks and decisions: Psychological and legal implications. Symposium conducted at the Annual Convention of the American Psychological Association, New York.

Thompson, D. W., \& Jason, L. A. (1988). Street gangs and preventive interventions. Criminal Justice and Behavior, 15, 323-333.

Thornburgh v. American College of Obstetricians and Gynecologists, 476 U.S. 747 (1968).

Wald, P. (1974). Making sense out of the rights of youth. Human Rights, 4, 13-29.

Webster v. Reproductive Health Services, 57 U.S.L.W. 5023 (U.S. July 3, 1989).

$\rightarrow$ Weithorn, L. A., \& Campbell, S. A. (1982). The competency of children to make informed treatment decisions. Child Development, 53, 1589-1598.

Zabin, M., Kanter, J., \& Ford, K. (1980). Sex and pregnancy in adolescence. Beverly Hills, CA: Sage.

Zimring, F. E. (1982). The changing legal world of adolescence. New York: The Free Press. 